\title{
Respiratory Muscle Blood Flow Distribution during
}

\section{Expiratory Resistance}

\author{
Charles H. Robertson, Jr., William L. Eschenbacher, and Robert L. Johnson, Jr. \\ From the Pauline and Adolph Weinberger Laboratory for Cardiopulmonary Research of the Department \\ of Internal Medicine, University of Texas Southwestern Medical School at Dallas, Dallas, Texas 75235
}

\begin{abstract}
A B S TRACT When work load on the respiratory system is increased the relative increase in blood flow to each of the muscles of breathing provides an index of how the augmented effort of breathing is partitioned among the different muscles. We have used a radioactive microsphere technique to measure blood flow to each of the muscles of respiration in supine dogs during unobstructed respiration and breathing against graded expiratory threshold loads. $79 \%$ of the augmented flow went to expiratory muscles; of this increased flow to expiratory muscles $74 \%$ went to abdominal wall muscles and $26 \%$ to internal intercostals. In our earlier studies of hyperventilation induced by $\mathrm{CO}_{2}$ rebreathing where expiratory work loads were low, $44 \%$ of the increase in flow went to expiratory muscles; of this, only $39 \%$ went to abdominal wall muscles and $61 \%$ to internal intercostals. During inspiratory resistance which produced small increases in expiratory work, $27 \%$ of the increase in blood flow went to expiratory muscles; of this, only $37 \%$ went to abdominal wall muscles and $63 \%$ to internal intercostals. These results suggest that the internal intercostals are predominantly used for expiration when expiratory work loads are low, whereas the abdominal wall muscles are predominantly used when loads are high.

For similar rates of pressure-volume work done on the lung, the total respiratory muscle blood flow is significantly greater during expiratory loads than during unobstructed hyperventilation or inspiratory loads. Thus, the abdominal wall muscles that are utilized for overcoming high pressure expiratory loads are relatively inefficient in converting metabolic energy into pressure-volume work.
\end{abstract}

W. L. Eschenbacher was supported by a predoctoral fellowship, U. S. Public Health Service Training grant HL 058182, from the National Heart and Lung Institute.

Received for publication 20 December 1976 and in revised form 24 March 1977.

\section{INTRODUCTION}

Previous attempts to define the muscles of respiration have utilized either anatomic inference or electromyography, both of which are subject to error and misinterpretation. The distribution of augmented blood flow among respiratory muscles as the work of breathing is increased should provide an accurate quantitative index of the distribution of muscular effort, since blood flow to skeletal muscle is proportional to effort expended by the muscle (1-3). In previous studies we have described the increases in blood flow observed in each muscle of respiration during mechanical ventilation and during quiet spontaneous breathing (4), during breathing against graded inspiratory resistances (5), and during unobstructed hyperventilation induced by the $\mathrm{CO}_{2}$ retention during rebreathing (4).

The present investigation was designed to compare the distribution of blood flow among the respiratory muscles during unobstructed breathing with that during graded expiratory threshold loads. The combined results of this study and the earlier ones represent a spectrum of inspiratory, expiratory, and combined loads imposed on the chest bellows. The different results allow a comparison of the sequence in which muscles of breathing are recruited as different loads are imposed and a comparison of the relative efficiency with which different kinds of imposed load can be overcome.

\section{METHODS}

Experimental protocol. Healthy mongrel dogs weighing 16-27 kg were anesthetized with sodium pentobarbital 25 $\mathrm{mg} / \mathrm{kg}$ intravenously; small increments were given subsequently to sustain adequate anesthesia but maintain the corneal reflex. A tracheostomy was performed and the endotracheal tube connected to a one-way Otis-McKerrow valve. An intraesophageal balloon was positioned in the distal 
esophagus and inflated with $1.0 \mathrm{ml}$ of air, a volume which had been shown to allow accurate measurement of externallyapplied pressure from +50 to $-50 \mathrm{~cm} \mathrm{H}_{2} \mathrm{O}$. The animal was then placed supine in a pressure-compensated flow plethysmograph (Fig. 1). It breathed to the outside of the box through separate, noncompressible, large bore inspiratory and expiratory tubes. Flow was measured as pressure drop across the screen pneumotachygraph $(400$ mesh, diameter $4.0 \mathrm{~cm})$ and pressure was measured with a Validyne DP-45 transducer (Validyne Engineering Corp., Northridge, Calif.). Pressure compensation was accomplished before each study by imposing volume sine waves simultaneously into the plethysmograph box and into a closed bottle containing the esophageal balloon connected to a pressure transducer; a fraction of box pressure was added to the integrated flow signal to close the loop formed by plotting esophageal balloon pressure with respect to box volume change. Compensation was adjusted before each experiment by placing inside the box styrofoam blocks approximately equal to the size of the experimental animal. The plethysmograph had a flat amplitude response and was in phase with the esophageal balloon to at least 8 cycles/s.

The animal breathed spontaneously either with no added load or with an increased expiratory threshold load. To create the load, the expiratory line was placed 10 or $20 \mathrm{~cm}$ below the surface of a water bath. After a 15-min equilibration period at each level of resistance, the studies described below were performed over $5 \mathrm{~min}$; then a new resistance was applied.

Work of breathing. Esophageal pressure was measured with a Statham PM131TC transducer (Statham Instruments, Oxnard, Calif.). Using a Sanborn Ampex model 2000 recorder (Ampex Corp., Redwood City, Calif.), pressure and plethysmographic thoracic gas volume were recorded simultaneously on electromagnetic tape. A computer program was developed to integrate the area between the pressurevolume curve and resting end-expiratory esophageal pressure

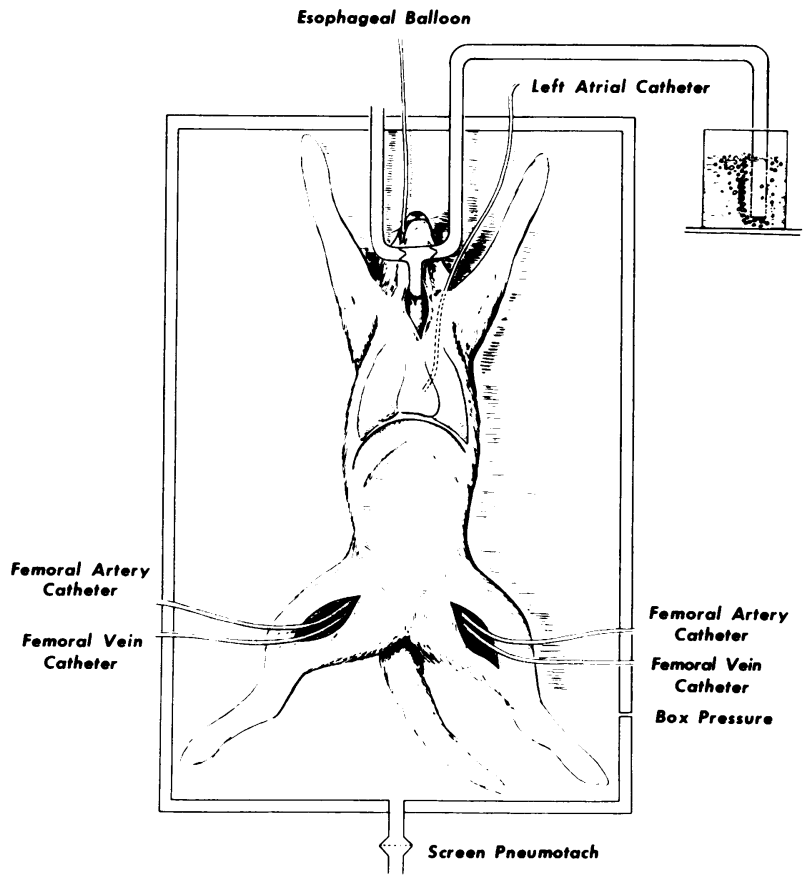

Figure 1 Animal preparation used in this study.

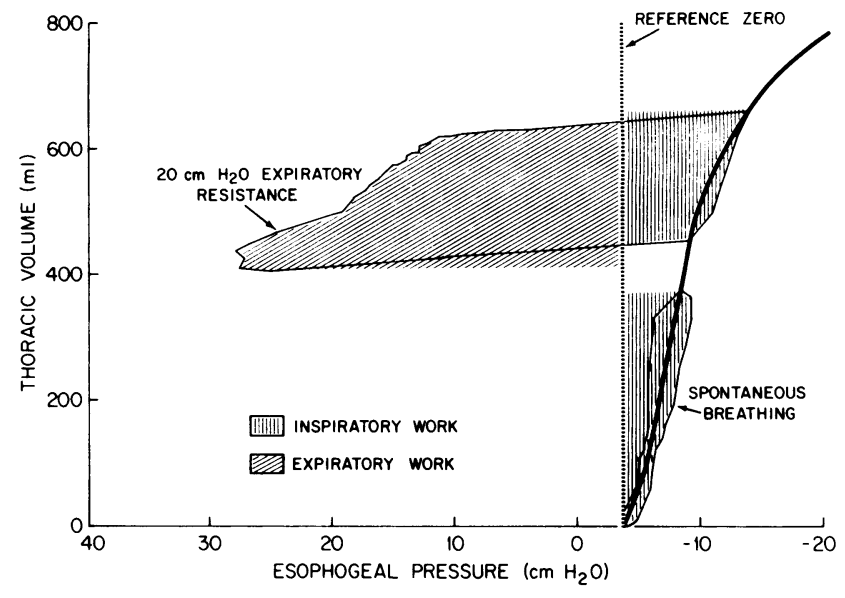

FIgURE 2 The work of breathing done on the lung was calculated by computer integration of the areas shown. In this representative tracing from one animal inspiratory work is the vertically shaded area and expiratory work is the horizontally shaded area. During unobstructed breathing almost all of the work is inspiratory. At $20 \mathrm{~cm} \mathrm{H}_{2} \mathrm{O}$ expiratory threshold load the majority of work is expiratory; nevertheless inspiratory work tends to be augmented by the shift to a higher functional residual capacity where inspiration must be accomplished against a higher mean negative pressure.

for both inspiration and expiration as shown in Fig. 2. This area has the dimensions of work and corresponds reasonably well to the work done on the lung by the chest wall, diaphragm, and abdominal muscles (6-8). The computer calculated work for each breath over a 5-min period at each level of expiratory resistance. These data were averaged and expressed as work per minute.

Blood flow to respiratory muscles. Blood flow per gram to each of the various respiratory muscles was measured by a radioactive microsphere technique described in detail previously (9-12). The modifications, validity, and reproducibility of this technique for measuring respiratory muscle blood flows were described in a previous communication (5). Absolute flow to a muscle was obtained as the product of flow per gram and average weight of the muscle determined in previous experiments (5). Total respiratory muscle blood flow was calculated by summing the totals of these muscles whose blood flow increased under the conditions of these experiments. The relative contributions of each muscle were estimated from the ratio of its flow to total respiratory muscle flow.

Cardiac output-blood gases. To assess the contribution of changes in cardiac output to the changes in flows seen in the respiratory and control muscles during expiratory resistance, cardiac output was measured by the indocyaninegreen dye dilution method employing a Lyons model DCCO04 computer (Physio-Tronics, Inc., Burbank, Calif.) Measurements were performed in triplicate and averaged. At each work level heparinized samples were withdrawn anaerobically from femoral artery. These were analyzed immediately for $\mathrm{PO}_{2}$ (313 Blood Gas Analyzer, Instrumentation Laboratory, Lexington, Mass.), $\mathrm{O}_{2}$ saturation (Instrumentation Laboratory Co-oximeter), and hemoglobin (Beckman DB Spectrophotometer, Beckman Instruments, Inc., Fullerton, Calif.).

Statistics. Statistical analysis was performed with the Student's $t$ test for paired data in all cases except where linear regressions are specified. 
TABLE I

Ventilation, Blood Gases, Work of Breathing, and Mean Pressures during Unobstructed Breathing and Expiratory Threshold Loads of 10 and $20 \mathrm{~cm} \mathrm{H}_{2} \mathrm{O}$

\begin{tabular}{|c|c|c|c|}
\hline & \multicolumn{3}{|c|}{ Imposed load } \\
\hline & None & $10 \mathrm{~cm} \mathrm{H}_{2} \mathrm{O}$ & $20 \mathrm{~cm} \mathrm{H}_{2} \mathrm{O}$ \\
\hline & \multicolumn{3}{|c|}{ mean $\pm S E$} \\
\hline \multicolumn{4}{|l|}{ Respiratory rate, } \\
\hline $\begin{array}{l}\text { Minute volume, liters } \\
\min \end{array}$ & $6.57 \pm 0.69$ & $4.48 \pm 0.44^{*}$ & $4.42 \pm 0.60^{*}$ \\
\hline $\mathrm{PaO}_{2}, m m \mathrm{Hg}$ & $90.6 \pm 8.9$ & $72.4 \pm 13.4$ & $58.6 \pm 13.0^{*}$ \\
\hline $\mathrm{PaCO}_{2}, \mathrm{~mm} \mathrm{Hg}$ & $39.4 \pm 3.9$ & $50.6 \pm 6.7^{*}$ & $62.0 \pm 10.3^{*}$ \\
\hline $\mathrm{pH}$, Units & $7.36 \pm 0.04$ & $7.28 \pm 0.06^{*}$ & $7.18 \pm 0.10^{*}$ \\
\hline $\mathrm{A}-\mathrm{a} \Delta \mathrm{PO}_{2}, m m \mathrm{Hg}$ & $19.4 \pm 10.7$ & $26.0 \pm 12.1$ & $28.4 \pm 9.8$ \\
\hline \multicolumn{4}{|l|}{ Work rate, Cal/min: } \\
\hline Inspiration & $0.71 \pm 0.12$ & $0.65 \pm 0.15$ & $0.84 \pm 0.15$ \\
\hline Expiration & $0.00 \pm 0.00$ & $1.00 \pm 0.22^{*}$ & $1.68 \pm 0.33^{*}$ \\
\hline Total & $0.71 \pm 0.12$ & $1.65 \pm 0.34^{*}$ & $2.52 \pm 0.56^{*}$ \\
\hline Inspiratory time, $s / \min$ & $16.6 \pm 1.1$ & $8.0 \pm 0.7^{*}$ & $8.0 \pm 1.1^{*}$ \\
\hline \multicolumn{4}{|l|}{ Mean inspiratory } \\
\hline pressure, $\mathrm{cm} \mathrm{H}_{2} \mathrm{O}$ & $-4.16 \pm 0.40$ & $-7.54 \pm 0.63^{*}$ & $-8.34 \pm 0.38 *$ \\
\hline
\end{tabular}

* Significantly changed from rest $(P<0.05)$.

\section{RESULTS}

Table I lists the changes in ventilation, blood gases and work of breathing observed during resting ventilation and while breathing against expiratory threshold loads of 10 and $20 \mathrm{~cm} \mathrm{H}_{2} \mathrm{O}$. Respiratory rate and minute volume decreased in the transition from resting ventilation to $10 \mathrm{~cm} \mathrm{H}_{2} \mathrm{O}$ expiratory load $(P<0.005$ and $P<0.003$, respectively) but did not change further as load increased to $20 \mathrm{~cm} \mathrm{H}_{2} \mathrm{O} . \mathrm{PaO}_{2}$ and $\mathrm{pH}$ decreased progressively $(P<0.03) ; \mathrm{PaCO}_{2}$ increased progressively $(P<0.03)$. Most of the decrease in arterial oxygen tension is explained by hypoventilation as the alveolar-arterial oxygen tension difference $\left(\mathrm{A}-\mathrm{a} \Delta \mathrm{PO}_{2}\right)^{1}$ did not change significantly $(P=0.32)$ and the small mean change was much less than the $\mathrm{PaO}_{2}$ decrement. The total work of breathing per minute increased almost fourfold $(P<0.01)$, almost all of which was due to expiratory work which increased from an immeasurable level to $1.68 \mathrm{Cal} / \mathrm{min}(P<0.005)$. Inspiratory work rate increased slightly on the highest load $(P<0.01)$.

The blood flows per gram to each of the muscles regarded as muscles of respiration by Miller et al. (13) are indicated in Table II. Those muscles to which flow increased significantly are graphed in Fig. 3. The transverse abdominal muscle had the greatest increase in flow per gram to a high of $0.73 \mathrm{ml} / \mathrm{g}$ per $\min (P<0.01)$. The internal oblique, internal intercostal, and external

\footnotetext{
${ }^{1}$ Abbreviations used in this paper: A-a $\Delta \mathrm{Po}_{2}$, alveolararterial oxygen tension difference; EMG, electromyogram; $\Delta \dot{Q} \mathbf{x} / \Delta \dot{Q} \mathbf{r s}$, fractional contribution of each muscle to the overall change in blood flow.
}

TABLE II

Blood Flow to Control Skeletal Muscles and to Muscles of Breathing* during Quiet Unobstructed Breathing and during 10 and $20 \mathrm{~cm} \mathrm{H}_{2} \mathrm{O}$ Expiratory Threshold Loads

\begin{tabular}{lccc}
\hline & \multicolumn{3}{c}{ Resistance } \\
\cline { 2 - 4 } & None & $10 \mathrm{~cm} \mathrm{H} \mathrm{H}_{2} \mathrm{O}$ & $20 \mathrm{~cm} \mathrm{H} \mathrm{H}_{2} \mathrm{O}$ \\
\hline & & $\mathrm{mllg}$ \\
Expiratory muscles & & & \\
Transverse ab- & & & \\
dominal & $0.09 \pm 0.02$ & $0.37 \pm 0.08 \ddagger$ & $0.73 \pm 0.10 \ddagger$ \\
Internal oblique & $0.05 \pm 0.01$ & $0.23 \pm 0.06 \ddagger$ & $0.43 \pm 0.08 \ddagger$ \\
Internal inter- & & & \\
costal & $0.07 \pm 0.00$ & $0.14 \pm 0.03 \ddagger$ & $0.33 \pm 0.09 \ddagger$ \\
External oblique & $0.04 \pm 0.01$ & $0.10 \pm 0.02 \ddagger$ & $0.22 \pm 0.04 \ddagger$ \\
Rectus abdominis & $0.03 \pm 0.01$ & $0.03 \pm 0.01$ & $0.04 \pm 0.01$ \\
Ileocostalis & $0.04 \pm 0.01$ & $0.05 \pm 0.01$ & $0.05 \pm 0.02$ \\
Inspiratory muscles & & & \\
Diaphragm & $0.15 \pm 0.02$ & $0.22 \pm 0.03 \ddagger$ & $0.47 \pm 0.12 \ddagger$ \\
External inter- & & & \\
costal & $0.09 \pm 0.04$ & $0.10 \pm 0.02$ & $0.17 \pm 0.04 \ddagger$ \\
Scalene & $0.07 \pm 0.03$ & $0.05 \pm 0.01$ & $0.05 \pm 0.01$ \\
Serratus dorsalis & $0.04 \pm 0.01$ & $0.04 \pm 0.00$ & $0.04 \pm 0.01$ \\
Serratus ventralis & $0.04 \pm 0.00$ & $0.04 \pm 0.00$ & $0.05 \pm 0.01$ \\
Control muscles & & & \\
Triceps brachii & $0.04 \pm 0.01$ & $0.05 \pm 0.01$ & $0.05 \pm 0.01$ \\
Pectoralis & $0.03 \pm 0.00$ & $0.05 \pm 0.01$ & $0.05 \pm 0.01$ \\
\hline
\end{tabular}

Data are given as mean $\pm \mathrm{SE}$.

* As defined anatomically by Miller et al. (13).

$\ddagger$ Significantly increased from rest $(P<0.05)$.

oblique also had progressive increases as the rate of expiratory work increased. The rectus abdominis and ileocostalis, listed as muscles of expiration by Miller et al. (13), did not exhibit augmented flows.

Among inspiratory muscles there were modest increases in blood flow to the diaphragm at each work load $(P<0.05)$ and to the external intercostals at the high load only $(P<0.05)$. The scalenes, serratus doralis, and serratus ventralis, other inspiratory muscles by anatomic position (13), did not show increased flows.

The triceps brachii and pectoralis muscles were included as control skeletal muscles to be sure that the changes in muscle flows observed were not a nonspecific response to hypercarbia or changed cardiac output. There was no significant change in blood flow to either muscle (Table II), so they were grouped as controls for Fig. 3.

Table III shows the total blood flow to those muscles whose flow increased during expiratory loading. Assuming that blood flow to a skeletal muscle is proportional to effort expended by that muscle (1-3), the fractional contribution of each muscle to the overall 


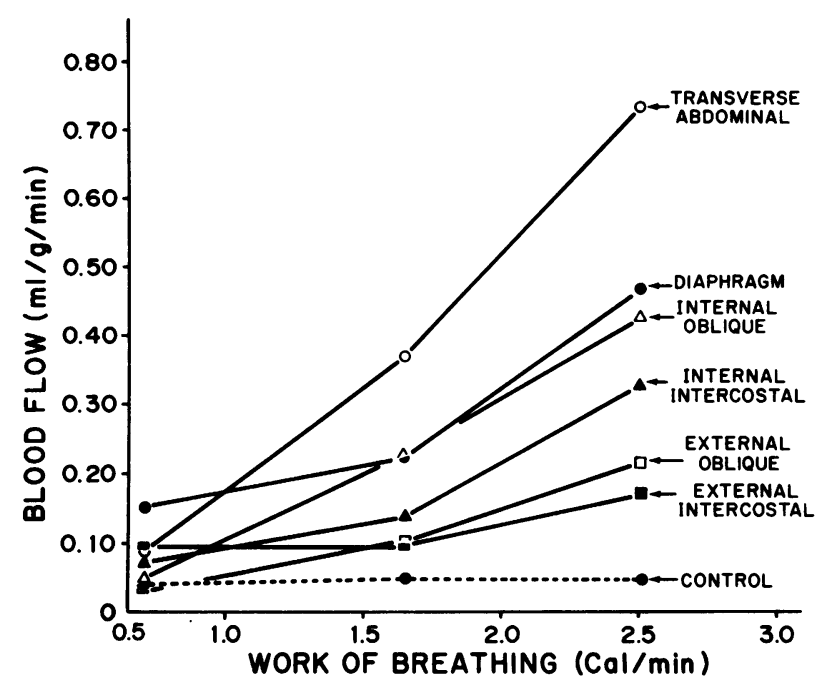

Figure 3 Blood flow per gram to each respiratory muscle which exhibited augmented flow is plotted against the rate of work of breathing.

change in blood flow ( $\Delta \dot{\mathrm{Q}} \mathrm{x} / \Delta \dot{\mathrm{Q} r s})$ should be proportional to the fraction of the increased muscular effort of breathing accomplished by that muscle. The transverse abdominal muscle received 36 and $29 \%$ of the increased flow on 10 and $20 \mathrm{~cm} \mathrm{H}_{2} \mathrm{O}$ expiratory threshold loads, respectively. Thus, it apparently accomplishes more of the muscular effort of breathing during expiratory resistance than its weight fraction (13\%) and more than any other muscle of respiration despite its relatively small size. The internal oblique also received a larger percentage of the increased blood flow than its weight fraction, but the internal intercostal and external oblique muscles received less than their weight fractions. The diaphragm, an inspiratory muscle, augmented its flow approximately in proportion to its weight fraction, but the external intercostal, the only other inspiratory muscle whose flow in- creased, made a minimal contribution to the overall increase in blood flow. Apparently, the diaphragm accomplishes the majority of the increased inspiratory effort under the condition of expiratory loading.

Cardiac output and blood pressure are plotted against the work of breathing in Fig. 4. The cardiac output decreased progressively on expiratory resistance, and blood pressure fell to a lesser extent; but neither reached statistical significance $(P=0.10$ and 0.15 , respectively). Thus, the increases in blood flow to the respiratory muscles were produced by major decreases in resistance in their individual vascular beds at a time when total peripheral resistance was increasing.

\section{DISCUSSION}

Assuming blood flow to skeletal muscle is proportional to muscular effort expended (1-3), an examination of the distribution of blood flow to each respiratory muscle should be an accurate way of determining the partition of effort among the muscles of breathing. The radioactive microsphere method used in this study has the advantage that each individual muscle's flow can be determined independent of adjacent muscles whose flow might also be changing, since at the completion of the study each individual muscle can be excised and counted separately. Previous attempts to examine the activity of respiratory muscles under various load conditions have either used pressurevolume changes or electromyograms (EMGs). The former method obviously can only look at whole muscle groups and cannot separate contributions by the various muscles. The latter is more specific but still suffers from the problems of transmission of EMG discharges from adjacent muscles and (or) the necessary intervention of placing electrodes in the muscle group which might locally affect its response pattern. These previous methods do have the advantage of being usable in human subjects.

TABLE III

Total Blood Flow to Muscles of Breathing during Quiet Unobstructed Breathing and during Expiratory Threshold Loads of 10 and $20 \mathrm{~cm} \mathrm{H}_{2} \mathrm{O}$

\begin{tabular}{|c|c|c|c|c|c|c|c|}
\hline & \multicolumn{5}{|c|}{ Resistor total blood flow } & & \\
\hline & \multirow{2}{*}{$\frac{\text { None }}{m l / m i n}$} & \multicolumn{2}{|c|}{$10 \mathrm{~cm} \mathrm{H}_{2} \mathrm{O}$} & \multicolumn{2}{|c|}{$20 \mathrm{~cm} \mathrm{H}_{2} \mathrm{O}$} & \multicolumn{2}{|c|}{ Muscle weight } \\
\hline & & $\mathrm{ml} / \mathrm{min}$ & $\begin{array}{c}\Delta Q x / \Delta Q r s \\
(\%)\end{array}$ & $\mathrm{ml} / \mathrm{min}$ & $\begin{array}{c}\Delta Q x / \Delta Q r s \\
(\%)\end{array}$ & $g$ & $\begin{array}{l}\% \text { of } \\
\text { total }\end{array}$ \\
\hline Transverse abdominal & 7.16 & 29.79 & 36 & 58.93 & 29 & 80.5 & 13 \\
\hline Internal intercostal & 10.16 & 19.21 & 15 & 45.66 & 20 & 139.2 & 22 \\
\hline External oblique & 5.54 & 16.00 & 17 & 34.06 & 16 & 158.4 & 26 \\
\hline Internal oblique & 3.19 & 14.71 & 19 & 27.67 & 14 & 65.1 & 10 \\
\hline Diaphragm & 15.54 & 23.21 & 12 & 48.48 & 18 & 103.6 & 17 \\
\hline External intercostal & 6.77 & 7.14 & 1 & 12.66 & 3 & 73.6 & 12 \\
\hline Total respiratory muscle & 48.36 & 110.06 & 100 & 227.46 & 100 & 620.4 & 100 \\
\hline
\end{tabular}


There were two changes occurring in our animals which might have affected blood flow to the respiratory muscles independent of effort. The cardiac output and blood pressure tended to fall during expiration against a threshold load as might be expected from the rise in mean intrathoracic pressure $(14,15)$. The fall in perfusion pressure would tend to decrease flow to muscle. At the same time hypercarbia was induced by expiratory loads and the consequent respiratory acidosis may cause muscular vasodilation (16). Nevertheless, the blood flow to nonrespiratory control muscles, i.e., to the triceps brachii and pectoralis, did not change, suggesting that these opposing influences were cancelling each other or that autoregulation was overriding. Thus, it is unlikely that hypercarbia or the falling blood pressure affected our results significantly.

During expiratory resistance there was a modest increase in inspiratory work, and blood flow to two inspiratory muscles (diaphragm and external intercostals) increased during breathing against expiratory threshold loads. Possible reasons for this were: $(a)$ a shift to higher lung volumes so that expiration was assisted by increased elastic recoil but increased inspiratory work was required to expand the lungs, chest, and abdomen during inspiration. Although lung volumes were not measured a higher functional residual capacity was suspected during expiratory loading because of the increased mean negative pressure during inspiration (Table I). Campbell et al. have previously demonstrated an increased functional residual capacity with similar threshold loads to expiration (17). (b) A change in the pattern of breathing to a more rapid inspiration and a slow expiration, requiring increased effort by inspiratory muscles. This was confirmed by measuring the time spent in active inspiration in these animals (see Table I).

However, the increase in diaphragmatic blood flow is more than expected for the modest increase in pressure-volume work rate observed. Agostoni and Rahn have demonstrated that the diaphragm actively contracts during maximal expiratory efforts (18). This diaphragmatic contraction occurs at any lung volume whenever the abdominal muscles exert a maximal expiratory effort, although it is greatest at low lung volumes and end-expiration (19). Although expiratory contraction of the diaphragm would not be registered as inspiratory work, metabolic energy requirements of the diaphragm would increase, requiring an increase in blood flow and oxygen delivery. Thus, expiratory contraction of the diaphragm may explain the apparent dissociation between inspiratory pressure volume work and inspiratory muscle blood flow in our animals.

On the basis of anatomic position all of the muscles listed as muscles of expiration in dogs in Table II might be expected to participate in overcoming an expiratory load (13). However, our results suggest that

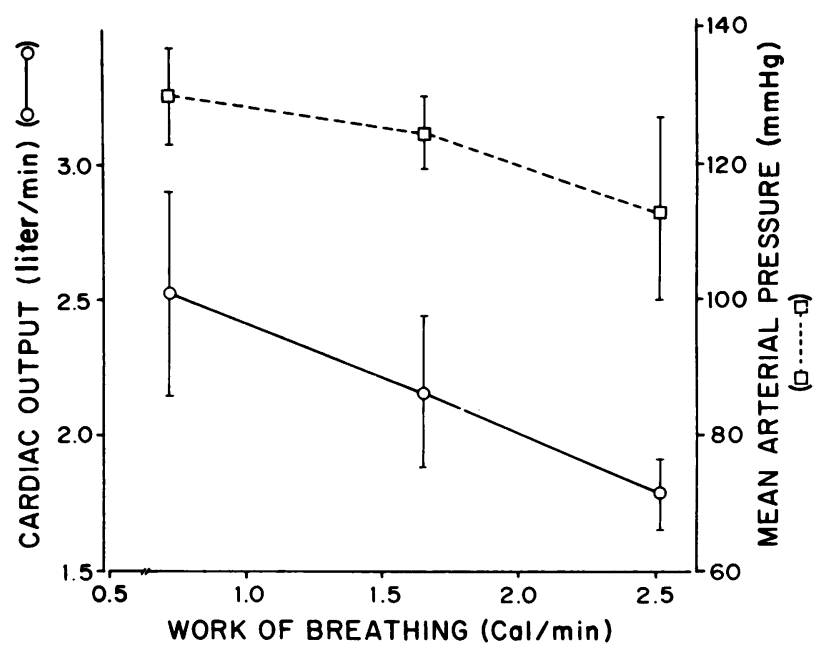

FIGURE 4 Changes in cardiac output and blood pressure observed during expiratory loading.

the rectus abdominis and ileocostalis muscles were not utilized during expiratory loading, as blood flow to these muscles did not increase even though expiratory work rate increased from 0 to $1.68 \mathrm{Gal} / \mathrm{min}$. It is conceivable nevertheless that these muscles might have been utilized for a different type of expiratory load or a greater increase in expiratory work than could be induced in these anesthetized animals. The transverse abdominal muscle appears to be the major muscle of expiration in the abdominal wall, as it receives about one-third of the total increased flow to respiratory muscles $(\Delta \dot{\mathrm{Q}} \mathrm{x} / \Delta \dot{\mathrm{Q}} \mathrm{rs})$ during expiratory loading (Table III). Collectively, the abdominal muscles received $74 \%$ of the blood flow increment to active expiratory muscles at the highest load; internal intercostals received only $26 \%$ of the total. So during large expiratory work loads the abdominal muscles presumably are consuming most of the energy requirements. However, during lower loads to expiration this was not the case. During inspiratory resistance where expiratory work did not increase to more than 0.5 $\mathrm{Cal} / \mathrm{min}, 63 \%$ of the increased flow to expiratory muscles went to the internal intercostals and only $37 \%$ to the abdominal wall muscles (5). Also, during unobstructed hyperventilation when expiratory work did not exceed $0.3 \mathrm{Cal} / \mathrm{min}$ despite a fivefold increment in ventilation, $61 \%$ of the increased blood flow to expiratory muscles went to the internal intercostals and only $39 \%$ to the abdominal muscles (4).

Thus, the active expiratory muscles in the order of their recruitment over a wide range of loads to expiration appear to be: $(a)$ the internal intercostals which are recruited first and accomplish the majority of the energy consumption of expiratory muscles when expiratory work is low (i.e., during normal, unobstructed hyperventilation or inspiratory resistance), (b) 
the transversus abdominis, $(c)$ internal obliques, and (d) external obliques. The last three are abdominal muscles and become increasingly important when high expiratory work loads are imposed.

During previous studies employing inspiratory resistance loads, blood flow to the internal intercostals reached $75 \mathrm{ml} / \mathrm{min}$ although the work of expiration reached an average of only $0.33 \mathrm{Cal} / \mathrm{min}(4)$. This is a much higher blood flow to the internal intercostals than that reached during expiratory resistance (46 $\mathrm{ml} / \mathrm{min}$ ) where expiratory work was $1.68 \mathrm{Cal} / \mathrm{min}$ (Fig. 5). However, it was noted during the highest inspiratory resistance load that the dogs' upper chest wall tended to cave in during inspiration while the abdomen and lower rib cage were expanded by vigorous, diaphragmatic contractions. Perhaps, as has been suggested by Jones et al. (20), the internal intercostals are used during heavy inspiratory load conditions to stabilize the rib spaces and minimize inspiratory collapse of the rib cage by contracting with the external

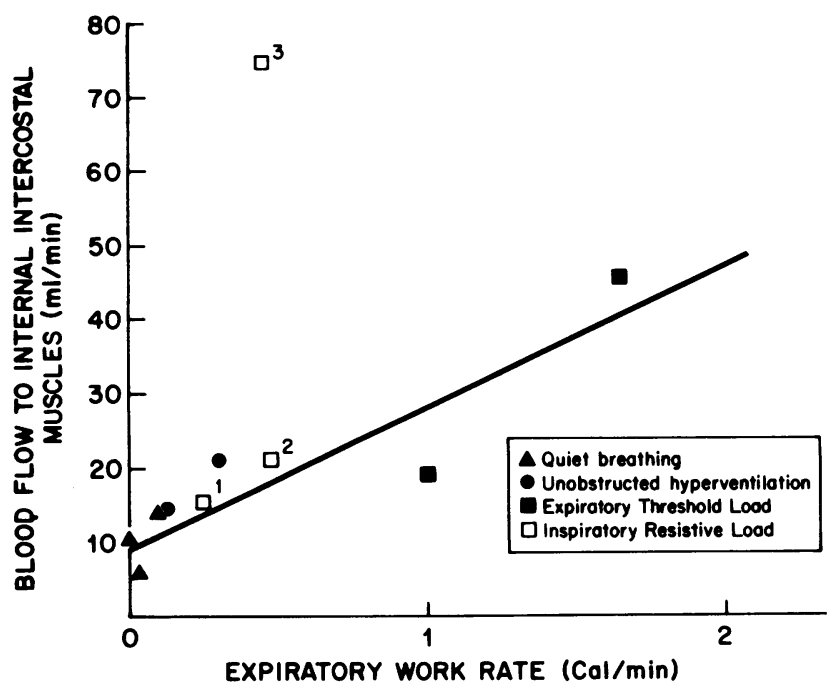

FIGURE 5 During quiet breathing, expiratory threshold loading and unobstructed hyperventilation (4) there is a good linear correlation $(r=0.912)$ between blood flow to internal intercostal muscles and work rate of exhalation. The regression line pertains to the closed symbols. The numbered open squares represent average data collected in dogs during inspiratory resistive loading (5). The open square labeled 1 reflects a turbulent inspiratory resistance load of $90 \mathrm{~cm} \mathrm{H} \mathrm{H}_{2} \mathrm{O}$ / (liters $/ \mathrm{s})^{2}$; that labeled 2 reflects a turbulent resistance of 300 $\mathrm{cm} \mathrm{H}_{2} \mathrm{O} /(\text { liters } / \mathrm{s})^{2}$; and that labeled 3 represents a turbulent resistance of $1,200 \mathrm{~cm} \mathrm{H}_{2} \mathrm{O} /(\text { liters } / \mathrm{s})^{2}$. The blood flow to internal intercostal muscles at the lower two inspiratory loads follows the expected relationship to expiratory work reflected by the regression line, but at the highest inspiratory resistance blood flow to internal intercostal muscles rises disproportionately (well outside three standard errors of the estimate). A possible explanation is that at these high inspiratory loads the internal intercostals contract during inspiration as well as during exhalation perhaps as a means of stabilizing the rib cage against inspiratory collapse. intercostals during inspiration. Thus, internal intercostals may perform an inspiratory as well as expiratory function.

Our results to a large degree corroborate earlier studies that used the electromyogram to determine the contribution of the various accessory muscles. Freund et al. observed no activity of abdominal expiratory muscles during quiet breathing (21). Similarly in our animals no work was being expended on expiration during quiet breathing and there was no augmentation in blood flow to expiratory muscles in the transition from mechanical ventilation to quiet spontaneous respiration (4). Campbell found little use of abdominal external oblique muscles with either hyperventilation or low levels of expiratory resistance (22). This is similar to our finding that the external oblique receives a much smaller increase in blood flow per gram than any other expiratory muscle that is recruited during expiratory resistance, inspiratory resistance, or unobstructed hyperventilation. It would appear that this muscle is primarily used for posture maintenance rather than respiration, as previously concluded by Campbell (22). Our results corroborate the EMG findings of Agostoni et al. (23), Campbell et al. (17), and Bishop and Bachofen $(24,25)$ that expiratory loading by itself augments diaphragmatic contractions. We were unable to confirm Campbell and Green's finding that the rectus abdominis is used during expiratory resistance (26). However, Campbell and Green used skin surface EMG electrodes and they may have picked up signals from the transverse abdominis or abdominal obliques during vigorous contractions, since increased rectus abdominis EMGs occurred only with very vigorous contractions and the signal was always less than that registered over the lateral abdominal wall muscles. Finally, we did not confirm over our relatively wide range of ventilatory stresses the use of the vast number of accessory muscles of inspiration and expiration described by EMG in man by Tokizane et al. (27). Those studies however involved multiple positions in which these muscles may have had roles in posture maintenance during vigorous breathing efforts and thus are difficult to interpret.

Since the blood flow to a muscle bears a direct relationship to oxygen consumption (1-3), the absolute blood flow to a muscle should vary directly with the metabolic energy expended by that muscle. The external mechanical work produced by that energy will depend on the mechanical efficiency of that muscle for the work being performed, the efficiency being a complex effect of the fiber arrangement within the muscle, the mechanical advantage of the muscle insertions, fiber type, opposing or augmenting contractions of other muscles, etc. Thus, the relative efficiency of the respiratory muscles in producing external mechanical work on the lungs should be inversely re- 
lated to the total blood flow to the respiratory muscles. This inverse relationship allows a comparison of the efficiency under the various conditions of expiratory threshold loads produced in this study vs. inspiratory resistive loads (5) and unobstructed hyperventilation produced by $\mathrm{CO}_{2}$ rebreathing in our earlier studies (4). Because of the complex mechanics of the combined thorax and abdomen, it would not be surprising if the relative efficiency of muscular contraction was different under these different load conditions. Fig. 6 shows the total blood flow to the muscles of breathing in these three studies plotted as a function of the rate of work of breathing. For any given rate of work, expiratory loads resulted in a much higher total blood flow to respiratory muscles than did either inspiratory loads or hyperventilation. Such data suggest that expiratory muscles are relatively inefficient in performing pressure-volume work on the lungs during threshold expiratory loads.

A majority of the increased blood flow to respiratory muscles during expiratory loading went to abdominal muscles ( $72 \%$ on $10 \mathrm{~cm} \mathrm{H}_{2} \mathrm{O}$ and $59 \%$ on $20 \mathrm{~cm} \mathrm{H}_{2} \mathrm{O}$ load, Table III), whereas only a minor percentage went to these muscles under the other two conditions. This difference suggests that the abdominal muscles may be required to generate high expiratory pressures but are at a mechanical disadvantage for generating efficient work on the lungs. For one thing they may be working against a diaphragm which contracts during forced expiration (18) as discussed earlier. Also, the positive intraabdominal pressure will tend to increase the rib cage diameter by tending to move the rib cage along its relaxation characteristic to higher volumes as described by Goldman and Mead (28). This will further deter the generation of a positive intrathoracic pressure and thus effective work done on the lung. Finally, while contraction of the transversus abdominis

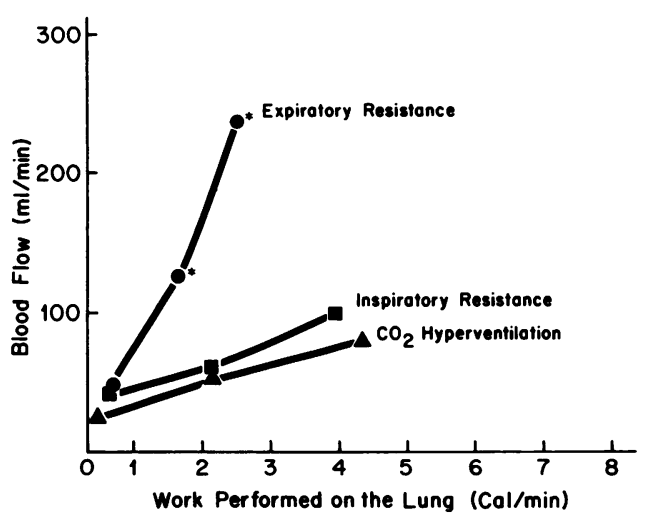

FIGURE 6 For similar rates of work performed on the lung $(\mathrm{Cal} / \mathrm{min})$ expiratory load $(\bullet)$ required a significantly greater total blood flow to respiratory muscles $(*=P<0.05)$ than did either inspiratory loading $(\square)$ or hyperventilation induced by $\mathrm{CO}_{2}$ rebreathing $(\boldsymbol{\Delta})$. will tend to increase rib cage volume by increasing intraabdominal pressure, contraction of the internal oblique and to a lesser extent the external obliques will exert a downward force on the costal margin, tending to decrease rib cage volume. In short, during expiratory loading the respiratory muscles apparently work against each other in a counterproductive way such that the overall efficiency falls.

Because of their inefficiency during expiratory obstruction, the respiratory muscles required large blood flows $(227 \mathrm{ml} / \mathrm{min})$ to deliver the oxygen necessary for relatively moderate work rates $(2.5 \mathrm{Cal} / \mathrm{min}$ on the highest load). At the same time cardiac output was 1.79 liters $/ \mathrm{min}$. Thus, at the highest load the respiratory muscles received $12.7 \%$ of the cardiac output. In patients with respiratory failure due to chronic obstructive lung disease a similar situation may exist. In such patients the combination of a limited cardiac output and significant hypoxemia often makes oxygen delivery marginal; hence, the inordinately large blood flow requirements of respiratory muscles working against an expiratory obstruction may be a critical factor in further limiting oxygen delivery to the vital organs.

\section{ACKNOWLEDGMENTS}

Mrs. Sharon Smith provided valuable assistance in typing and proofreading the manuscript.

\section{REFERENCES}

1. Kramer, K., F. Obel, and W. Quensel. 1939. Untersuchungen über den Muskelstoffwechsel des Warmebluters. III. Mitteilung. Die Sauresoffaufnahme des Muskels während Rhythmisches Tätiqkeit. Pfluegers Archiv Gesamte Physiol. Menschen Tiere. 241: 717-729.

2. Hirvonen, L., and R. R. Sonnenschein. 1962. Relation between blood flow and contraction force in active skeletal muscle. Circ. Res. 10: 94-104.

3. Barcroft, H. 1963. Circulation in skeletal muscle. Handb. Physiol. 2 (Sec. 2. Circulation): 1353-1385.

4. Robertson, C. H., Jr., M. A. Pagel, and R. L. Johnson, Jr. 1977. The distribution of blood flow, oxygen consumption, and work output among the respiratory muscles during unobstructed hyperventilation. J. Clin. Invest. 59: 43-50.

5. Robertson, C. H., Jr., G. H. Foster, and R. L. Johnson, Jr. 1977. The relationship of respiratory failure to the oxygen consumption of, lactate production by, and distribution of blood flow among respiratory muscles during increasing inspiratory resistance. J. Clin. Invest. 59: 31-42.

6. McGregor, M., and M. R. Becklake. 1961. The relationship of oxygen cost of breathing to respiratory mechanical work and respiratory force. J. Clin. Invest. 40: 971-980.

7. Otis, A. B. 1964. The work of breathing. Handb. Physiol. 1 (Sec. 3. Respiration): 463-476.

8. Campbell, E. J. M., E. Agostoni, and J. N. Davis. 1970. Energetics. In The Respiratory Muscles, Mechanics and Neural Control. W. B. Saunders Co., Philadelphia, Pa. 115-137.

9. Rudolph, A. M., and M. A. Heymann. 1967. Circulation of the fetus in utero: methods for studying distribution 
of blood flow, cardiac output and organ blood flow. Circ. Res. 21: 163-184.

10. Forsyth, R. P., B. I. Hoffbrand, and K. L. Melmon. 1970. Redistribution of cardiac output during hemorrhage in the unanesthetized monkey. Circ. Res. 27: 311-320.

11. Buckberg, G. D., J. C. Luck, D. B. Payne, J. I. E. Hoffman, J. P. Archie, and D. E. Fixler. 1971. Some sources of error in measuring regional blood flow with radioactive microspheres. J. Appl. Physiol. 31: 598-604.

12. Archie, J. P., D. E. Fixler, D. J. Ullyot, J. I. E. Hoffman, J. R. Utley, and E. L. Carlson. 1973. Measurement of cardiac output with and organ trapping of radioactive microspheres. J. Appl. Physiol. 35: 148-154.

13. Miller, M. E., G. C. Christensen, and H. E. Evans. 1964. Myology. In Anatomy of the Dog. W. B. Saunders Co., Philadelphia, Pa. 131-266.

14. Hamilton, W. F., R. A. Woodbury, and H. T. Harper. 1936. Physiological relationships between intrathoracic, intraspinal arterial pressures. J. A. M. A. (J. Am. Med. Assoc.). 107: 853-856.

15. Lenfant, C., and B. J. Howell. 1960. Cardiovascular adjustments in dogs during continuous pressure breathing. J. Appl. Physiol. 15: 425-428.

16. Kontos, H. A., M. D. Thomas, A. Lombana, C. O. Watlington, and F. Jessee. 1971. Vasodilator effects of local hypercapnic acidosis in dog skeletal muscle. Am. J. Physiol. 200: 1569-1572.

17. Campbell, E. J. M., C. J. Dickinson, O. D. Dinnick, and J. B. L. Howell. 1961. The immediate effects of threshold loads on the breathing of men and dogs. Clin. Sci. (Oxf.). 21: $309-320$.

18. Agostoni, E., and H. Rahn. 1960. Abdominal and thoracic pressures at different lung volumes. J. Appl. Physiol. 15: $1087-1092$
19. Agostoni, E., G. Gurtner, G. Torri, and H. Rahn. 1966. Respiratory mechanics during submersion and negativepressure breathing. J. Appl. Physiol. 21: 251-258.

20. Jones, D. S., R. J. Beargie, and J. E. Pauly. 1953. An electromyographic study of some muscles of costal respiration in man. Anat. Rec. 117: 17-24.

21. Freund, F., A. Roos, and R. B. Dodd. 1964. Expiratory activity of the abdominal muscles in man during general anesthesia. J. Appl. Physiol. 19: 693-697.

22. Campbell, E. J. M. 1957. The effects of increased resistance to expiration on the respiratory behavior of the abdominal muscles and intra-abdominal pressure. $J$. Physiol. (Lond.). 136: 556-562.

23. Agostoni, E., G. Sant' Ambrogio, and H. del Portillo Carrasco. 1960. Electromyography of the diaphragm in man and transdiaphragmatic pressure.J.Appl. Physiol. 15: 1093-1097.

24. Bishop, B. 1967. Diaphragm and abdominal muscle responses to elevated airway pressures in the cat. J. Appl. Physiol. 22: 959-965.

25. Bishop, B., and H. Bachofen. 1972. Vagal control of ventilation and respiratory muscles during elevated pressures in the cat. J. Appl. Physiol. 32: 103-112.

26. Campbell, E. J. M., and J. H. Green. 1953. The expiratory function of the abdominal muscles in man. An electromyographic study. J. Physiol. (Lond.). 120: 409-418.

27. Tokizane, T., K. Kawamata, and H. Tokizane. 1952. Electromyographic studies on the human respiratory muscles. Jpn. J. Physiol. 2: 232-247.

28. Goldman, M., and J. Mead. 1973. Mechanical interaction between the diaphragm and rib cage.J. Appl. Physiol. 35: 197-204. 